\title{
Effects of ACEI/ARB in hypertensive patients with type 2 diabetes mellitus: a meta-analysis of randomized controlled studies
}

\author{
Guang Hao ${ }^{1}$, Zengwu Wang ${ }^{1 *}$, Rui Guo ${ }^{2}$, Zuo Chen ${ }^{1}$, Xin Wang ${ }^{1}$, Linfeng Zhang ${ }^{1}$ and Wei Li ${ }^{3}$
}

\begin{abstract}
Background: The effects of angiotensin-converting enzyme (ACE) inhibitors and angiotensin II receptor blockers (ARBs) on cardiovascular (CV) risk in hypertensive patients with type 2 diabetes mellitus (T2 DM) are uncertain. Our objective was to analyze the effects of ACE/ARBs, on the incidence of myocardial infarction, stroke, CV events, and all-cause mortality in hypertensive patients with T2 DM.

Method: PubMed and Embase databases were searched through January 2014 to identify studies meeting a priori inclusion criteria and references in the published articles were also reviewed. Two investigators independently extracted the information with either fixed-effect model or random-effect model to assess the effects of ACE/ARBs treatment in hypertensive patients with T2 DM.

Results: Ten randomized controlled studies were included with a total of 21,871 participants. Overall, treatment with ACE/ARBs in hypertensive patients with T2 DM was associated with a statistically significant $10 \%$ reduction in CV events, pooled hazard ratio (HR) of 0.90 [95\% confidence intervals (Cl): 0.82-0.98] with no heterogeneity $\left(I^{2}=19.50 \% ; P=0.275\right)$; and $17 \%$ reduction in CV mortality, pooled HR of 0.83 [95\% Cl: $0.72-0.96$ ] with no heterogeneity $\left(I^{2}=0.9 \% ; P=0.388\right)$. ACE/ARBs was not associated with Ml, stroke and all-cause mortality.
\end{abstract}

Conclusions: Treatment with ACE/ARBs results in significant reduction in CV events and mortality in hypertensive patients with T2 DM.

\section{Background}

Hypertension and type 2 diabetes (T2 DM) frequently coexist, and patients with this combination are at a higher risk for cardiovascular (CV) events than those suffering from hypertension or T2 DM alone [1-3]. Most (60\% to 80\%) people with T2 DM die of CV complications, and up to $75 \%$ of specific $\mathrm{CV}$ complications have been attributed to high blood pressure (BP) [4]. The improved treatment of hypertension has been associated with a marked reduction in death and hospitalization from $\mathrm{CV}$ disease [5]. The use of angiotensin-converting enzyme (ACE) inhibitors or angiotensin II receptor blockers (ARBs), could reduce both CV morbidity and mortality

\footnotetext{
* Correspondence: wangzengwu@foxmail.com

'Division of Prevention \& Community Health, National Center for

Cardiovascular Disease, Fuwai Hospital, Peking Union Medical College \&

Chinese Academy of Medical Sciences, No. 167 Beilishi Road Xicheng District,

Beijing 100037, China

Full list of author information is available at the end of the article
}

across populations that apart from hypertension [6-8], had other co-morbid conditions.

The beneficial effect of ACE inhibitor treatment on allcause mortality for hypertensive patients was well established in a recent meta-analysis [9]. However, the effect of ACE/ARBs on CV risk in hypertensive patients with $\mathrm{T} 2$ DM remains controversial. The Heart Outcomes Prevention Evaluation (HOPE) study showed that treatment with Ramipril reduced cardiovascular events in patients with diabetes, out of which 56\% were hypertensive [10]. The Fosinopril Versus Amlodipine Cardiovascular Events Randomized Trial (FACET) and Captopril Prevention Project (CAPPP) study demonstrated that the ACE inhibitors fosinopril could significantly reduce risk of major vascular events in hypertensive diabetic patients compared with controls [11,12]. However, other studies like the Irbesartan Diabetic Nephropathy Trial (IDNT) or The Action in Diabetes and Vascular disease: preterAx and diamicroN-MR Controlled Evaluation 
(ADVANCE) trial failed to find such a beneficial effect in hypertensive patients with T2 DM [13,14].

To our best knowledge, there is no meta-analysis or RCT focused on the effect of ACE/ARBs on CV risk in hypertensive patients with T2 DM, although these classes of drug were recommended for these patients by the guidelines of 2013 European Society of Hypertension (ESH) and of the European Society of Cardiology (ESC) and the eighth report of Joint National Committee (JNC 8) [15,16]. However, the evidence derived from papers focused on the Individuals with and without Diabetes Mellitus separately [6].

The objective of the present study is to review randomized clinical trials (RCT) were revising the effect of antihypertensive treatment using ACE/ARBs on incidence of myocardial infarction (MI), stroke, CV events, and all-cause mortality in hypertensive patients with T2 DM.

\section{Methods}

\section{Search strategy and study selection}

We performed a systematic search of Pubmed and Embase databases through January 2014 for relevant studies performed in hypertensive patients with T2 DM. Subject headings and key words used for the literature search were as follows: 1) mortality, CV diseases, MI and stroke; 2) hypertension and diabetes; 3) angiotensin-converting enzyme inhibitors and angiotensin receptor blockers; 4) RCTs. The titles, abstracts and full-texts were reviewed independently by two reviewers. The criteria for eligible studies were as follows: 1) Randomized clinical trials in hypertensive patients with T2 DM comparing active treatment with ACE inhibitors or ARBs with control treatment (placebo, life style changes, active antihypertensive treatment with drugs other than ACEI or ARB); 2) The endpoints were mortality, CV events, MI or stroke; 3) Hazard ratios (HR) were calculated with the corresponding confidence intervals (CI). Following this search, references of published articles were also reviewed. Finally, 10 RCTs were selected, out of them, IDNT data was used in two articles for the analysis of different endpoint events [14,17] (Figure 1).

\section{Data extraction}

We collected the following information from each study: first author name or study title, year of publication, country of origin, gender, follow-up period, class of antihypertensive drugs, disease outcome, the number of trial participants, HR with the corresponding $95 \% \mathrm{CI}$, and the mean diastolic and systolic BP at baseline. Two investigators independently calculated and tabulated the data using a standard extraction formula. Any discrepancies were discussed by the research team and were resolved. In addition, we used the modified Jadad scale to determine the quality of the studies [18].

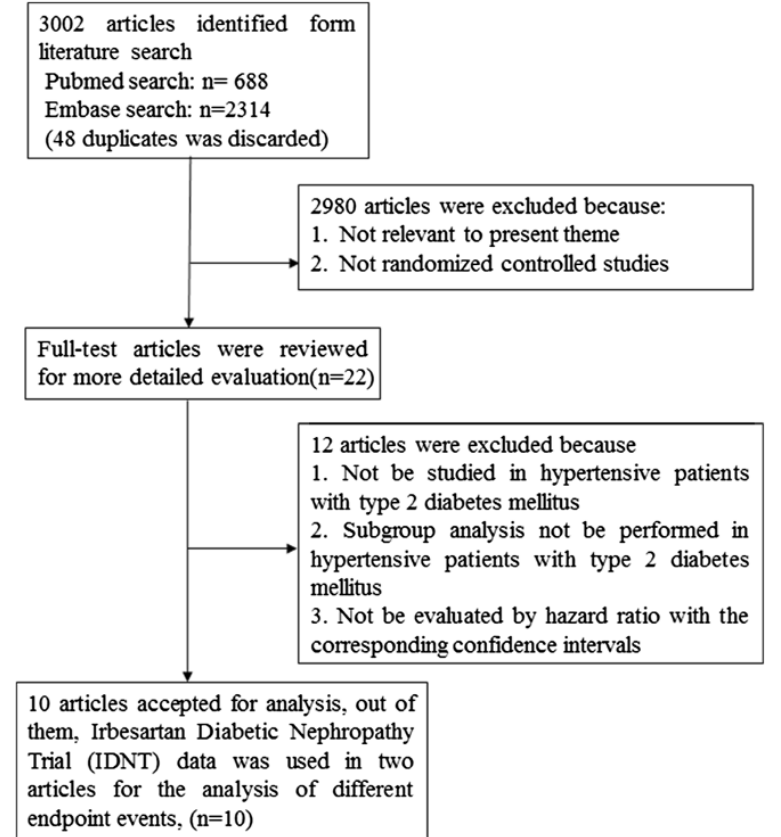

Figure 1 Flow chart of study selection.

\section{Endpoint definition}

The endpoints of this pooled analysis were MI, stroke, CV events, and CV and all-cause mortality. Stroke including fatal or nonfatal stroke, $\mathrm{MI}$ including fatal or nonfatal acute $\mathrm{MI}$, and CV events is according to trial-specific definitions, including coronary artery bypass, percutaneous transluminal coronary angioplasty, death from cardiovascular causes, nonfatal myocardial infarction, heart failure, etc. Not all studies included every endpoint. Data on all-cause mortality were available in 7 trials, $\mathrm{CV}$ mortality in 4 trials, $\mathrm{CV}$ events in 8 trials, MI in 5 trials, and stroke in 7 trials.

\section{Statistical analysis}

The combined risk estimates were computed with either fixed-effect model or random-effect model, if heterogeneity existed. The Cochrane $\mathrm{Q}$ statistics (significance level of $P<0.10$ ) and the $\mathrm{I}^{2}$ statistics were used to assess the heterogeneity of HR across studies. Since the characteristics were not consistent from study-to-study, we further conducted sensitivity analysis and stratified analyses to explore the possible explanation for heterogeneity. For sensitivity analysis, the effect of a single study on overall risk factors was investigated by omitting one study at a time. Stratified analyses were performed by control group (placebo-controlled or active antihypertensive drugs, baseline systolic BP, reduction of systolic BP, and class of antihypertensive drugs (ACE inhibitors or ARBs). The possibility of publication bias was assessed using the Begg and Egger test. We also performed the visual inspection of Begg funnel plots in which $\log$ RRs were plotted against their SEs. All 
analyses were conducted using STATA version 11.2 (Stata Corp LP, College Station, TX). A value of $P<0.05$ was defined as statistically significant.

\section{Results}

\section{Characteristics of the studies}

Table 1 shows the 10RCTs' characteristics of 21,871 hypertensive patients with T2 DM, published between 1998 and 2012. Two RCTs were conducted in the United States $[11,17], 3$ in Europe [12,19,20], 2 in Japan [21,22], and 3 were multicenter studies $[13,14,23]$. IDNT data was used in two articles for the analysis of different endpoint events $[14,17]$. The length of follow-up ranged from 2.5 to 9 years. All studies were conducted in hypertensive patients with T2 DM except for one (the respondents were diabetics, $59 \%$ of those were hypertensive) [13]. The number of respondents ranged from 257 to 11,140 (total 21,871) participants. BP decreased more in ACE/ ARBs group (mean difference: systolic BP $4.14 \mathrm{~mm} \mathrm{Hg}$ and diastolic BP $1.63 \mathrm{mmHg}$ ) compared with those assigned to control treatment. Study quality generally was good (Additional file 1: Table S1).

\section{All-cause mortality}

Treatment with ACE/ARBs did not reduce significantly all-cause mortality (HR: 0.91, 95\% CI: $0.83-1.00, P=0.062$ ); the degree of heterogeneity in the treatment effect across all trials was low $\left(\mathrm{I}^{2}=21.0 \%\right)$ and non-significant $(P=0.210$, Figure 2a).

\section{CV mortality}

Treatment with RAAS achieved a $17 \%$ significant reduction in CV mortality (HR: $0.83,95 \%$ CI: $0.72-0.96, P=0.012$ ), the degree of heterogeneity in the treatment effect across all trials was low $\left(\mathrm{I}^{2}=0.9 \%\right)$ and non-significant $(P=0.388$, Figure $2 b)$.

\section{MI and stroke}

In all 5 trials grouped together, MI risk was not reduced significantly (HR: $0.85,95 \%$ CI: $0.53-1.37, P=0.511$ ), with a higher heterogeneity across all trials $\left(\mathrm{I}^{2}=66.5 \%, P=0.018\right.$, Figure 2c). In all 8 trials grouped together, we did not find a statistically significant reduction in stroke with ACE/ ARBs treatment (HR: 0.99, 95\% CI: $0.85-1.15, P=0.855$ ); the degree of heterogeneity in the treatment effect across all trials was low $\left(\mathrm{I}^{2}=0.0 \%\right)$ and non-significant $(P=0.745$, Figure 2d).

\section{CV events}

In all 8 trials grouped together, treatment with $\mathrm{ACE} /$ ARBs was associated with a statistically significant $10 \%$ significant reduction in CV events (HR: 0.90, 95\% CI: $0.82-0.98, P=0.019)$, with non-significant heterogeneity between studies $\left(\mathrm{I}^{2}=19.50 \%, P=0.275\right.$, Figure 2$)$.

\section{Stratified and sensitivity analysis}

For stratified analysis of key characteristics see Additional file 1: Table S2. Exclusion of any single study did not substantially alter the result in analysis of different endpoints.

\section{Publication bias}

The funnel-plot asymmetry, and the P-values using an Egger regression test were 0.97 (all-cause mortality), 0.41 (CV events), 0.81 (CV mortality), 0.80 (MI) and 0.55 (stroke), indicating no evidence for publication bias.

\section{Discussion}

Although the ESH/ESC and JNC8 [15,16] recommend $A C E$ inhibitors or ARB as the preferred therapy in hypertensive patients with T2 DM, the effect of ACE/ARBs on mortality in hypertensive patients with T2 DM remains not unequivocally accepted. In an effort to evaluate the effects of $\mathrm{ACE} / \mathrm{ARBS}$ on $\mathrm{CV}$ outcomes in hypertensive patients with T2 DM, we performed a systematic review of the literature and analyzed 10 RCTs. Overall, the results of our review showed that treatment with the ACE/ARBs was associated with a $10 \%$ reduction in $\mathrm{CV}$ events and, $17 \%$ reduction in $\mathrm{CV}$ mortality. Previous studies and metaanalyses evaluating the effects of ACE/ARBs on the overall risk for $\mathrm{CV}$ events in hypertensive patients have yielded conflicting results. The Asia Pacific Cohort Studies Collaboration (APCSC) study indicated that major CV risk was reduced to a comparable extent in hypertensive individuals with or without diabetes while on an ACE inhibitor-based treatment, or other antihypertensive regimens [24]. The NAVIGATOR Study also failed to find a reduction of CV risk in patients with impaired glucose tolerance and established $\mathrm{CV}$ disease using valsartan and lifestyle modification [25]. On the other hand, in another study [26], initiation of antihypertensive treatment involving ACE inhibitors in hypertensive patients and with $8 \%$ T2 DM, appeared to lead to better outcomes than treatment with diuretic agents. A recent meta-analysis showed that ACE/ARBs were associated with a $5 \%$ reduction in all-cause mortality and a 7\% reduction in $\mathrm{CV}$ mortality; the treatment effect resulted entirely from the class of ACE inhibitors. No mortality reduction could be demonstrated with ARB treatment in the hypertension population [9]. Bangalore and colleagues pooled 37 RCTs and showed that ARBs reduce the risk of stroke, heart failure, and new onset diabetes compared with controls in general hypertensive [27]. In our study, we could not ascertain whether the observed reduction in $\mathrm{CV}$ events (10\%) and reduction in CV mortality (17\%) among hypertensive patients with T2DM could be was attributed to treatment with ACE inhibitors or treatment with ARBs.

In our meta-analysis, beneficial effects were only found in ADVANCE (for CV and all-cause mortality), FACET (for CV event) and CAPPP (for CV mortality and MI) 
Table 1 Baseline characteristics of study population in 10 trials

\begin{tabular}{|c|c|c|c|c|c|c|c|c|c|}
\hline Study/author & Public year & Country & Age (year) & Total $(\mathrm{I} / \mathrm{C})^{*}$ & Female (\%) & follow-up years & Medications used $(\mathrm{I} / \mathrm{C})^{*}$ & $\begin{array}{l}\text { BP }(m m H g) ~ I(S B P / D B P ; \\
\text { C(SBP/DBP }\end{array}$ & $\begin{array}{l}\text { Reduction of BP }(\mathrm{mmHg})^{\#} \\
\text { I(SBP/DBP; C(SBP/DBP) }\end{array}$ \\
\hline UKPDS [19] & 1998 & United Kingdom & 56 & $400 / 358$ & 48 & over 9 & Captopril/Atenolol & 159/94; 159/93 & 15/10; 16/12 \\
\hline FACET [11] & 1998 & United State & 63 & 189/191 & 41 & $2.5-3.5$ & Fosinopril/Amlodipine & $170 / 95 ; 171 / 94$ & $19 / 8 ; 13 / 8$ \\
\hline RENAAL [23] & 2001 & Multi-centers & 60 & $751 / 762$ & 37 & 3.4 & Losartan/Placebo & $152 / 82 ; 153 / 82$ & $12 / 8 ; 11 / 8$ \\
\hline CAPPP [12] & 2001 & Sweden/Finland & $25-66$ & $309 / 263$ & 38 & 6.1 & Captopril/Conventional drugs & $164 / 97 ; 163 / 97$ & $8 / 4 ; 10 / 5$ \\
\hline IDNT $[14,17] \&$ & $2001 / 2003$ & Multi-centers & $30-70$ & $579 / 569$ & 32 & 2.6 & Irbesartan/Placebo & $160 / 87 ; 158 / 87$ & 20/10; 16/7 \\
\hline ADVANCE [13] & 2007 & Multi-centers & 66 & $5,569 / 5,571$ & 43 & 4.3 & Perindopril/Placebo & $145 / 81 ; 145 / 81$ & $5.6 / 2.2^{\#}$ \\
\hline CASE-J [21] & 2010 & Japan & 64 & $1,011 / 1,077$ & 44 & 3.3 & Candesartan/Amlodipine & $160 / 88 ; 160 / 88$ & - \\
\hline DEMAND [20] & 2011 & Italy/Slovenia & $\geq 40$ & $127 / 127$ & 37 & 3.8 & Delapril/Placebo & $147 / 87 ; 147 / 88$ & $11 / 6 ; 9 / 5$ \\
\hline NHS [22] & 2012 & Japan & 63 & $575 / 575$ & 34 & 3.2 & Valsartan/Amlodipine & $145 / 82 ; 144 / 81$ & $14 / 9 ; 13 / 8$ \\
\hline
\end{tabular}

UKPDS = United Kingdom Prospective Diabetes Study Group, FACET = Fosinopril Versus Amlodipine Cardiovascular Events Randomized Trial, RENAAL = Reduction of Endpoints in NIDDM with the Angiotensin II

Antagonist Losartan, CAPPP = The Captopril Prevention Project, IDNT = Irbesartan Diabetic Nephropathy Trial, ADVANCE = The Action in Diabetes and Vascular disease: preterAx and diamicroN-MR Controlled Evaluation, Antagonist Losartan, CAPPP $=$ The Captopril Prevention Project, IDNT = Irbesartan Diabetic Nephropathy Trial, ADVANCE = The Action in Diabetes and Vascular disease: 1 Pr.
CASE-J = candesartan antihypertensive survival evaluation in Japan, DEMAND = Delapril and Manidipine for Nephroprotection in Diabetes, NHS = NAGOYA HEART Study.

CASE- $=$ candesartan antihypertensive survival evaluation in Japan, $\mathrm{DEMAND}=$ Delapril and Manidipine for Nephroprotection in Diabetes, NHS = NAGOYA HEART Study.
$* \mathrm{I} / \mathrm{C}=$ Intervention/Control, SBP = systolic blood pressure, DBP = diastolic blood pressure; $\#$ reduction of SBP/DBP in intervention group compared with in placebo; - not give detail information; \&IDNT data was used in two $* \mid / C=$ Intervention/Control, $\mathrm{SBP}=$ systolic blood $\mathrm{p}$
articles for the analysis of different endpoint events. 


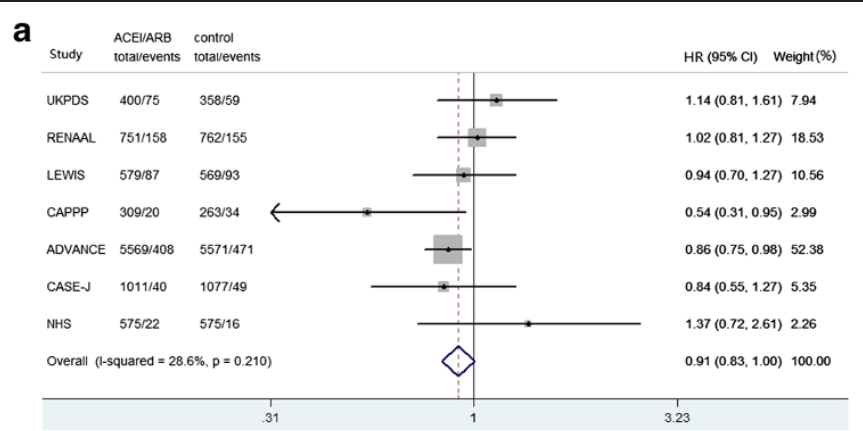

b

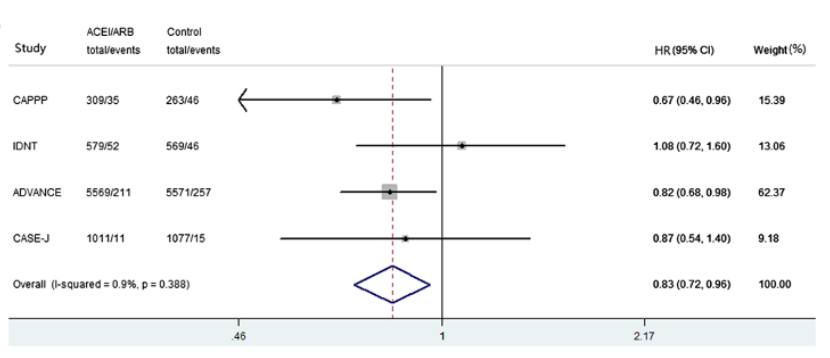

C

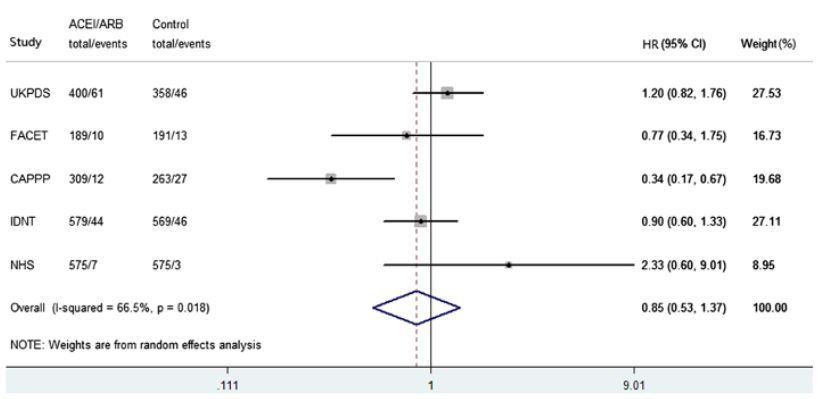

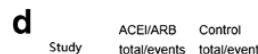

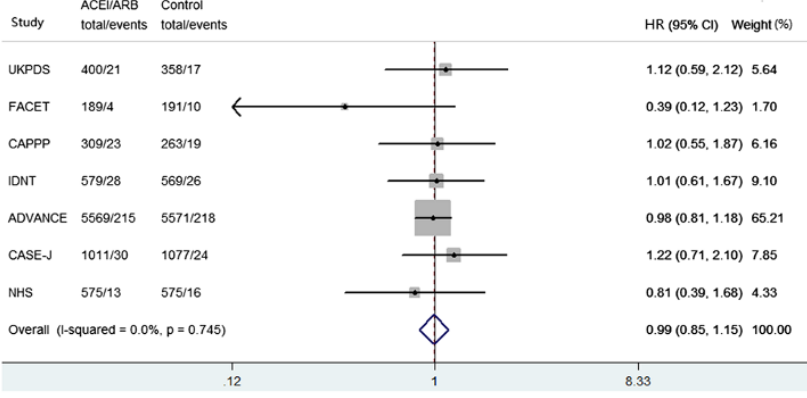

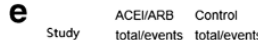

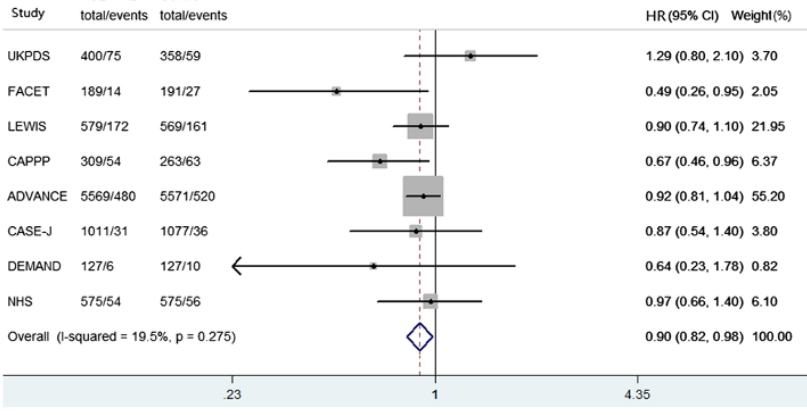

Figure 2 All-cause mortality (a), CV mortality (b), MI (c), stroke (d), and CV events (e) treatment effect of ACE/ARBs in all included trials. $\mathrm{CV}=$ cardiovascular, $\mathrm{Ml}=$ myocardial infarction, $\mathrm{HR}=$ hazard ratio, $\mathrm{Cl}=$ confidence interval. 
study, i.e. studies where ACE inhibitors were used [11-13]. However, stratified analysis of all-cause mortality and CV events failed to find an association both with the ACE inhibitor group and the ARB group.

There was marginal statistically significant effect of ACE/ ARBs on the all-cause mortality in hypertensive patients with T2DM $(P=0.062)$. A recent meta-analysis also found the ACEIs significantly reduced the risk of all-cause mortality by $13 \%$ in diabetes [28]. More studies should be performed to confirm the effect of ACEI/ARBs in hypertensive patients with T2DM.

The beneficial effect on $\mathrm{CV}$ events might be attributed mainly to differences in systolic BP [29]. In the Systolic Hypertension in the Elderly Program (SHEP) study, elderly persons with T2 DM derived more benefit from aggressive systolic BP lowering in reduction of $\mathrm{CV}$ than those without diabetes [30]. Additional benefit of aggressive BP lowering in the diabetic population was observed in a sub-analysis of Systolic Hypertension in Europe (SystEur) Trial. In that trial, although systolic BP was reduced by a comparable amount in each group, the risk reduction in mortality from $\mathrm{CV}$ disease was $13 \%$ in non-diabetic patients versus $76 \%$ for the diabetic patients [31]. There is weaker evidence that the effect of BP lowering between different drug classes is varied. Law and colleagues [32] pooled 354 RCTs and found that ACE inhibitors, calcium antagonists, and five categories of drug produced similar reductions in BP. We did not find a significant effect of BP lowering in stratified analysis, which may be due to lower statistical power. Therefore, further specific RCTs need to be performed to evaluate the BP lowering effect of Various ACE/ARBs in hypertensive patients with T2DM.

Several limitations of our analysis have to be mentioned. Firstly, our results are subject to limitations inherent to any meta-analysis based on pooling of data from different trials, including use of different definitions for $\mathrm{CV}$ events, different dosages of the active and control drug, different follow-up times, optimal BP target, combination treatment and participants with other concomitant conditions or background therapy. Although we could not find a differential result in sensitivity or stratified analyses, it was impossible to accurately estimate the effect of ACE/ARBs in patients with T2 DM. Secondly, one study did not report HR with $95 \%$ CI when a significant result was found [33] and it was not included in our analysis. This issue probably resulted in an underestimation of the effect of ACE/ARBs.

\section{Conclusion}

This meta-analysis, which involved almost 21,871 hypertensive patients with T2 DM, demonstrated that ACE/ARBs as a class of antihypertensive drugs were associated with a significant $10 \%$ reduction effect of $\mathrm{CV}$ events and $17 \%$ reduction in $\mathrm{CV}$ mortality when compared with control or active antihypertensive regimens with drugs other than ACEI or ARB. Stratified subgroup analysis according to class of BP-lowering regimens and different control group failed to differentiate between ACE inhibitors or ARB effect on CV outcomes. More studies should be performed to clarify if the beneficial effect on CV events and $\mathrm{CV}$ mortality among hypertensive patients with T2DM was derived from ACEIs, or ARBs.

\section{Additional file}

Additional file 1: Table S1. Risk assessment of bias used modified Jadad score. Table S2. Stratified Analyses of Pooled Hazard Ratio of ACEI/ ARB and cardiovascular risk.

\section{Competing interests}

The authors declare that they have no competing interests.

\section{Authors' contributions}

ZWW and GH are the primary authors who were responsible for study design. GH and RG collected data. GH analyzed the data and drafted the manuscript. All authors revised and approved the final version for publication.

\section{Acknowledgments}

The authors report no conflicts of interest. The authors alone are responsible for the content and writing of the paper.

\section{Author details}

${ }^{1}$ Division of Prevention \& Community Health, National Center for Cardiovascular Disease, Fuwai Hospital, Peking Union Medical College \& Chinese Academy of Medical Sciences, No. 167 Beilishi Road Xicheng District, Beijing 100037, China. ${ }^{2}$ Chinese medical association publishing house, No.42 Dongsi Street Dongcheng District, Beijing 100037, China. ${ }^{3}$ National Center for Cardiovascular Disease, Fuwai Hospital, Peking Union Medical College \& Chinese Academy of Medical Sciences, No. 167 Beilishi Road Xicheng District, Beijing 100037, China.

Received: 8 August 2014 Accepted: 17 October 2014 Published: 25 October 2014

\section{References}

1. Yamagishi S: Cardiovascular disease in recent onset diabetes mellitus. J Cardiol 2011, 57(3):257-262.

2. Assmann $G$, Schulte $H$ : Diabetes mellitus and hypertension in the elderly: concomitant hyperlipidemia and coronary heart disease risk. Am J Cardiol 1989, 63(16):33H-37H.

3. Mancia G: The association of hypertension and diabetes: prevalence, cardiovascular risk and protection by blood pressure reduction. Acta Diabetol 2005, 42(Suppl 1):S17-S25.

4. Sowers JR, Epstein M, Frohlich ED: Diabetes, hypertension, and cardiovascular disease: an update. Hypertension 2001, 37(4):1053-1059.

5. Campbell NR, Brant R, Johansen H, Walker RL, Wielgosz A, Onysko J, Gao RN, Sambell C, Phillips S, McAlister FA: Increases in antihypertensive prescriptions and reductions in cardiovascular events in Canada. Hypertension 2009, 53(2):128-134.

6. Turnbull F, Neal B, Algert C, Chalmers J, Chapman N, Cutler J, Woodward M, MacMahon S: Effects of different blood pressure-lowering regimens on major cardiovascular events in individuals with and without diabetes mellitus: results of prospectively designed overviews of randomized trials. Arch Intern Med 2005, 165(12):1410-1419.

7. Yusuf S, Sleight P, Pogue J, Bosch J, Davies R, Dagenais G: Effects of an angiotensin-converting-enzyme inhibitor, Ramipril, on cardiovascular events in high-risk patients. The heart outcomes prevention evaluation study investigators. N Engl J Med 2000, 342(3):145-153.

8. Fox KM: Efficacy of perindopril in reduction of cardiovascular events among patients with stable coronary artery disease: randomised, 
double-blind, placebo-controlled, multicentre trial (the EUROPA study). Lancet 2003, 362(9386):782-788.

9. van Vark LC, Bertrand M, Akkerhuis KM, Brugts JJ, Fox K, Mourad JJ, Boersma E: Angiotensin-converting enzyme inhibitors reduce mortality in hypertension: a meta-analysis of randomized clinical trials of renin-angiotensin-aldosterone system inhibitors involving 158,998 patients.

Eur Heart J 2012, 33(16):2088-2097.

10. Heart Outcomes Prevention Evaluation (HOPE) Study Investigators: Effects of Ramipril on cardiovascular and microvascular outcomes in people with diabetes mellitus: results of the HOPE study and MICRO-HOPE substudy. Heart outcomes prevention evaluation study investigators. Lancet 2000, 355(9200):253-259.

11. Tatti P, Pahor M, Byington RP, Di Mauro P, Guarisco R, Strollo G, Strollo F: Outcome results of the Fosinopril versus amlodipine cardiovascular events randomized trial (FACET) in patients with hypertension and NIDDM. Diabetes Care 1998, 21(4):597-603.

12. Niskanen L, Hedner T, Hansson L, Lanke J, Niklason A: Reduced cardiovascular morbidity and mortality in hypertensive diabetic patients on first-line therapy with an ACE inhibitor compared with a diuretic/ beta-blocker-based treatment regimen: a subanalysis of the Captopril Prevention Project. Diabetes Care 2001, 24(12):2091-2096.

13. Patel A, MacMahon S, Chalmers J, Neal B, Woodward M, Billot L, Harrap S, Poulter N, Marre M, Cooper M, Glasziou P, Grobbee DE, Hamet P. Heller S, Liu LS, Mancia G, Mogensen CE, Pan CY, Rodgers A, Williams B: Effects of a fixed combination of perindopril and indapamide on macrovascular and microvascular outcomes in patients with type 2 diabetes mellitus (the ADVANCE trial): a randomised controlled trial. Lancet 2007, 370(9590):829-840

14. Berl T, Hunsicker LG, Lewis JB, Pfeffer MA, Porush JG, Rouleau JL, Drury PL, Esmatjes E, Hricik D, Parikh CR, Raz I, Vanhille P, Wiegmann TB, Wolfe BM, Locatelli F, Goldhaber SZ, Lewis EJ: Cardiovascular outcomes in the Irbesartan diabetic nephropathy trial of patients with type 2 diabetes and overt nephropathy. Ann Intern Med 2003, 138(7):542-549.

15. James PA, Oparil S, Carter BL, Cushman WC, Dennison-Himmelfarb C, Handler J, Lackland DT, LeFevre ML, MacKenzie TD, Ogedegbe O, Smith SC Jr, Svetkey LP, Taler SJ, Townsend RR, Wright JT Jr, Narva AS, Ortiz E: 2014 evidence-based guideline for the management of high blood pressure in adults: report from the panel members appointed to the Eighth Joint National Committee (JNC 8). JAMA 2014, 311(5):507-520

16. Taylor J: $2013 \mathrm{ESH} / \mathrm{ESC}$ guidelines for the management of arterial hypertension. Eur Heart J 2013, 34(28):2108-2109.

17. Lewis EJ, Hunsicker LG, Clarke WR, Berl T, Pohl MA, Lewis JB, Ritz E, Atkins RC, Rohde R, Raz I: Renoprotective effect of the angiotensin-receptor antagonist irbesartan in patients with nephropathy due to type 2 diabetes. N Engl J Med 2001, 345(12):851-860.

18. Jadad AR, Moore RA, Carroll D, Jenkinson C, Reynolds DJ, Gavaghan DJ, McQuay HJ: Assessing the quality of reports of randomized clinical trials: is blinding necessary? Control Clin Trials 1996, 17(1):1-12.

19. UK Prospective Diabetes Study Group: Efficacy of atenolol and captopril in reducing risk of macrovascular and microvascular complications in type 2 diabetes: UKPDS 39. BMJ 1998, 317(7160):713-720.

20. Ruggenenti P, Lauria G, lliev IP, Fassi A, llieva AP, Rota S, Chiurchiu C, Barlovic DP, Sghirlanzoni A, Lombardi R, Penza P, Cavaletti G, Piatti ML, Frigeni B, Filipponi M, Rubis N, Noris G, Motterlini N, Ene-lordache B, Gaspari F, Perna A, Zaletel J, Bossi A, Dodesini AR, Trevisan R, Remuzzi G: Effects of manidipine and delapril in hypertensive patients with type 2 diabetes mellitus: the delapril and manidipine for nephroprotection in diabetes (DEMAND) randomized clinical trial. Hypertension 2011, 58(5):776-783.

21. Nakao K, Hirata M, Oba K, Yasuno S, Ueshima K, Fujimoto A, Ogihara T, Saruta T: Role of diabetes and obesity in outcomes of the candesartan antihypertensive survival evaluation in Japan (CASE-J) trial. Hypertens Res 2010, 33(6):600-606

22. Muramatsu T, Matsushita K, Yamashita K, Kondo T, Maeda K, Shintani S, Ichimiya S, Ohno M, Sone T, Ikeda N, Watarai M, Murohara T: Comparison between valsartan and amlodipine regarding cardiovascular morbidity and mortality in hypertensive patients with glucose intolerance: NAGOYA HEART Study. Hypertension 2012, 59(3):580-586.

23. Brenner BM, Cooper ME, de Zeeuw D, Keane WF, Mitch WE, Parving HH, Remuzzi G, Snapinn SM, Zhang Z, Shahinfar S: Effects of losartan on renal and cardiovascular outcomes in patients with type 2 diabetes and nephropathy. N Engl J Med 2001, 345(12):861-869.
24. Kengne AP, Patel A, Barzi F, Jamrozik K, Lam TH, Ueshima H, Gu DF, Suh I, Woodward M: Systolic blood pressure, diabetes and the risk of cardiovascular diseases in the Asia-Pacific region. J Hypertens 2007, 25(6):1205-1213.

25. McMurray JJ, Holman RR, Haffner SM, Bethel MA, Holzhauer B, Hua TA, Belenkov Y, Boolell M, Buse JB, Buckley BM, Chacra AR, Chiang FT, Charbonnel B, Chow CC, Davies MJ, Deedwania P, Diem P, Einhorn D, Fonseca V, Fulcher GR, Gaciong Z, Gaztambide S, Giles T, Horton E, Ilkova H, Jenssen T, Kahn SE, Krum H, Laakso M, Leiter LA, et al: Effect of valsartan on the incidence of diabetes and cardiovascular events. N Engl I Med 2010, 362(16):1477-1490

26. Wing $L M$, Reid $C M$, Ryan $P$, Beilin $L$, Brown $M A$, Jennings $G L$, Johnston $C l$, McNeil JJ, Macdonald GJ, Marley JE, Morgan TO, West MJ: A comparison of outcomes with angiotensin-converting-enzyme inhibitors and diuretics for hypertension in the elderly. N Engl J Med 2003, 348(7):583-592.

27. Bangalore S, Kumar S, Wetterslev J, Messerli FH: Angiotensin receptor blockers and risk of myocardial infarction: meta-analyses and trial sequential analyses of 147020 patients from randomised trials. BMJ 2011, 342:d2234.

28. Cheng J, Zhang W, Zhang X, Han F, Li X, He X, Li Q, Chen J: Effect of angiotensin-converting enzyme inhibitors and angiotensin II receptor blockers on all-cause mortality, cardiovascular deaths, and cardiovascular events in patients with diabetes mellitus: a meta-analysis. JAMA Intern Med 2014, 174(5):773-785.

29. Julius S, Kjeldsen SE, Weber M, Brunner HR, Ekman S, Hansson L, Hua T, Laragh J, McInnes GT, Mitchell L, Plat F, Schork A, Smith B, Zanchetti A: Outcomes in hypertensive patients at high cardiovascular risk treated with regimens based on valsartan or amlodipine: the VALUE randomised trial. Lancet 2004, 363(9426):2022-2031.

30. Curb JD, Pressel SL, Cutler JA, Savage PJ, Applegate WB, Black H, Camel G, Davis BR, Frost PH, Gonzalez N, Guthrie G, Oberman A, Rutan GH, Stamler J: Effect of diuretic-based antihypertensive treatment on cardiovascular disease risk in older diabetic patients with isolated systolic hypertension. JAMA 1996, 276(23):1886-1892.

31. Tuomilehto J, Rastenyte D, Birkenhager WH, Thiis L, Antikainen R, Bulpitt CJ, Fletcher AE, Forette F, Goldhaber A, Palatini P, Sarti C, Fagard R: Effects of calcium-channel blockade in older patients with diabetes and systolic hypertension. Systolic Hypertension in Europe Trial Investigators. N Engl J Med 1999, 340(9):677-684.

32. Law MR, Wald NJ, Morris JK, Jordan RE: Value of low dose combination treatment with blood pressure lowering drugs: analysis of 354 randomised trials. BMJ 2003, 326(7404):1427.

33. Estacio RO, Jeffers BW, Hiatt WR, Biggerstaff SL, Gifford N, Schrier RW: The effect of nisoldipine as compared with enalapril on cardiovascular outcomes in patients with non-insulin-dependent diabetes and hypertension. N Engl J Med 1998, 338(10):645-652

doi:10.1186/1471-2261-14-148

Cite this article as: Hao et al:: Effects of ACEl/ARB in hypertensive patients with type 2 diabetes mellitus: a meta-analysis of randomized controlled studies. BMC Cardiovascular Disorders 2014 14:148.

\section{Submit your next manuscript to BioMed Central and take full advantage of:}

- Convenient online submission

- Thorough peer review

- No space constraints or color figure charges

- Immediate publication on acceptance

- Inclusion in PubMed, CAS, Scopus and Google Scholar

- Research which is freely available for redistribution 